\title{
Satisfaction among hospital staff nurses on nurse staffing calculation-performance- oriented calculation based on Indonesian National Nurses Association (INNA) on information system
}

\author{
Rani Kawati Damanik*, Adventy Riang Bevy Gulo
}

Sari Mutiara Indonesia University, Nursing Science Study Program, Indonesia.

${ }^{*}$ Corresponding author. E-mail: rani140387@gmail.com

\begin{abstract}
Background: The Indonesian National Nurses Association (INNA) has a method and tool for staffing calculationperformance-oriented calculation based on information system

Purpose: To identify of satisfaction among hospital staff nurses on nurse staffing calculation-performanceoriented calculation based on Indonesian National Nurses Association (INNA)

on information system

Method: The technique of determining the sample using the Cohen effect size (d) formula, the total sample is 30 nurses, divided by two groups, each group comprise 15 nurses the as control group and intervention group 15 . The pre-post test done for both groups. The training given to participants for two days and following by measured to identify of satisfaction among hospital staff nurses twice to control and intervention groups using a questionnaire.

Results: The Kolmogorov Smirnov normality test and finding the data had abnormally distributed $(p<0.05)$, and following by the Mann Whitney test. The results showed that all the participants showed an increase in nurse satisfaction on nurse staffing calculation-performance-oriented calculation based on Indonesian National Nurses Association (INNA)

Conclusion: There is a difference in the level of satisfaction between a control group and an intervention with a range of 4.66 points. Using nurse staffing calculation-performance-oriented calculation based on Indonesian National Nurses Association (INNA) on information system, it applicable and reasonable to nurses to calculate nurse staffing in the hospital.
\end{abstract}

Keywords: Satisfaction; Hospital; Staff nurses; Calculation; Performance; Indonesian National Nurses Association (INNA); Information system

\section{INTRODUCTION}

Information systems have an important role in nursing activities (Alaei, Valinejadi, Zarein \& Salar, 2018). Base on of Disease Control and Prevention (CDP) in America reports that information systems can increase efficiency (Herlambang, Aknuranda, \& Saputra, 2017). The procedure for making information systems can be done in stages, namely: 1) Visual Basic (VB) is a programming environment from Microsoft where programmers can use graphic design to select and modify selected parts which are first coded and written in programming language basic, then 2 ) Microsoft SQL Server 2000 is a software product that functions to store and retrieve data as requested by other software applications, be it the same computer or on another computer (Adegboyega, \& Aniefiok, 2014).
Nursing information systems can improve the quality of nursing practice and the efficiency and administration in nursing so that it has been widely considered for application. The perceived usefulness is to improve system quality, and ease of use. The perceived ease of use in the use of quality information. The use of information systems has a significant effect on nurse satisfaction. Usefulness is also felt in aligning service quality. So that the information system has a very significant effect on nurse satisfaction (Lin, 2017).

The role of nurses is considered very important in providing health services to patients by paying attention to improving service quality. The relationship between job satisfaction of nurses and the quality of the information system in the hospital gives a very big contribution. The relationship between job satisfaction of nurses and the quality 
Satisfaction among hospital staff nurses on nurse staffing calculation-performance-oriented calculation based on Indonesian National Nurses Association (INNA) on information system

of the information system in the hospital is positive and significant $(p=0.000)$, with $(p<0.05)$ which means that nurses are satisfied with services in the form of information systems (Hakami, et al., 2020).

Nurses' perceptions about utilization, quality and satisfaction with the use of information systems. The nurse indicates that the information system is a source for clear, accurate and current data and improves nurse performance. So in other words the information system can overcome the challenges faced by nurses in nursing services. The results of this study indicate that the benefits felt in the use of information systems are to provide convenience to improve quality. The ease that is felt by users and the improvement of information quality has a significant effect on nurse satisfaction with the use of nursing information systems (Mansoori, Benjamin, Ngwakongnwi, \& Abdulla, 2019).

The successful application of information systems, especially in nursing, depends on the perception and acceptance of users. Therefore, it is very important to understand the perception, readiness and willingness of nurses to adapt electronic documentation. The findings reveal significant overall and unit improvements in nurses' perceptions post implementation of an electronic nursing documentation program. A weak positive relationship is formed between perceptions and utility acceptance of nurses exposed to electronic nursing documentation programs (Chand, \& Sarin, 2019). Information technology is very important to improve the quality of health services and is used in the health sector. The use of technology used by nurses is very significant in improving the quality of service (Orhan, 2019). Based on this, researchers are interested in conducting a study entitled the effect of the INNA method information system on satisfaction in the calculation of nurses at Medan Hospital.

\section{RESEARCH METHODS}

A quasi-experimental research with an approach post test with a control group (posttest only with control group design). This research conducted at the Imelda Hospital, Medan City, in 2019-2020. Determination of the sample with the effect size (d) using the Cohen formula. The determination of the sample by criteria as nurses who have at least a Diploma III in nursing education; had a worked experience at least 1 year. Other confounding variables such as age, work experience, education. The observation sheet is to measure the time used by nurses to calculate personnel using the system or not; The sample of 30 participants and divided into 2 groups of control and intervention, and each of 15 participants; an intervention group given socialization, workshop and simulation with a training material on how to operate a power calculation information system with the INNA formula that has installed on a computer/laptop, then direct practice in a day attended by 5 participants would take 3 days and following by post-test for both groups.

The test including answering the questionnaire and observation sheets to determine a satisfaction levels using information systems. The nurse satisfaction questionnaire consisted of 20 question items adopted from The DeLone and McLean Model of Information Systems and then tested the validity and reliability by the researcher with the assessment criteria: 1 = Strongly disagree, 2 = Disagree, $3=$ Agree and $4=$ Strongly agree. The result of the validity test $(\mathrm{CVI})$ of 3 experts is 0.80 then the reliability test results got a Cronbach's Alpha value of 0.98 from the results of the pilot study at the hospital, which is the same type as the hospital under study.

Data analysis used univariate to explain the description of the characteristics of the variables, presented in a frequency distribution table. And following by analyzing the efficiency of staffing calculation-performance-oriented calculation based on Indonesian National Nurses Association (INNA) on information system. Then the value post-test was tested for normality using the Kolmogorov Smirnov and not normally distributed $(p<0.05)$, so the data was tested using the Mann Whitney test. Nurse satisfaction criteria are Satisfied (score 1120) and dissatisfied (score 0-10) 
Satisfaction among hospital staff nurses on nurse staffing calculation-performance-oriented calculation based on Indonesian National Nurses Association (INNA) on information system

RESULTS

Table 1. Demographic Characteristics of Respondents $\mathrm{N}=30$

\begin{tabular}{|c|c|c|c|c|c|c|}
\hline \multirow[t]{2}{*}{ Demography } & \multirow[b]{2}{*}{$\mathbf{n}$} & \multicolumn{2}{|c|}{ Control Group } & \multicolumn{3}{|c|}{ Intervention Group } \\
\hline & & $\%$ & $M \pm S D$ & $\mathbf{n}$ & $\%$ & $M \pm S D$ \\
\hline Age (Years)(Range: 21-37) & & & $27.40 \pm 5.422$ & & & $27.67 \pm 5.407$ \\
\hline Work Experience (Years)(Range: 0-13) & & & $5.80 \pm 5.294$ & & & $4.80 \pm 4.814$ \\
\hline \multicolumn{7}{|l|}{ Gender: } \\
\hline Male & 2 & 13.3 & & 3 & 20.0 & \\
\hline Female & 13 & 86.7 & & 12 & 80.0 & \\
\hline \multicolumn{7}{|l|}{ Level of education: } \\
\hline Diploma in Nursing & 3 & 20.0 & & 4 & 26.7 & \\
\hline Bachelor's degree + Ners & 12 & 80.0 & & 11 & 73.3 & \\
\hline \multicolumn{7}{|l|}{ Nurse Satisfaction: } \\
\hline Satisfied & 2 & 13.3 & & 13 & 86.7 & \\
\hline unsatisfied & 13 & 86.7 & & 2 & 13.3 & \\
\hline
\end{tabular}

Based on table 1. Frequency distribution of implementing nurses based on age range 21-37 years where the control group is obtained mean 27.40 with a standard deviation of 5.422 and in the intervention group the mean was 27.67 with a standard deviation of 5.407. Based on work experience, the range of $0-13$ years where the control group obtained a mean of 5.80 with a standard deviation of 5,294 and in the intervention group a mean of 4.80 with a standard deviation of 4,814 was obtained. The majority of respondents were female as many as 13 people $(86.7 \%)$ and in the control group and 12 people $(80.0 \%)$ in the intervention group. Based on the highest education level, namely bachelor's degree, 12 nurses $(80.0 \%)$ in the control group and 11 people $(73.3 \%)$ in the intervention group. Based on the satisfaction of nurses, most of the nurses were dissatisfied as many as 13 people $(86.7 \%)$ in the control group, while in the intervention group some respondents were satisfied as many as 13 people $(86.7 \%)$.

Table 2. Distribution of Respondents Based on Nurse Satisfaction

\begin{tabular}{lccccccc}
\hline Variable & Mean & SE & SD & Min & Max & Z & Sig.(2-tailed) \\
& & & & & & & \\
\hline Nurse Satisfaction & 9.27 & 0.907 & 3.515 & 5 & 18 & -3.742 & 0.000 \\
Control & 13.93 & 0.777 & 3.011 & 8 & 19 & & \\
Intervention & & &
\end{tabular}

Based on table 2. it can be seen that nurse satisfaction has a different value between the control group and the intervention based on the Mean value of 4.66 , then the SE value (standard error) has a difference of 0.13 and based on SD (standard deviation) has a difference of 0.504 , a difference in the Min value of 3 and a difference in the Max value of 1 . Based on the results of the analysis of the difference in the efficiency of the calculation of nurses between the control and intervention groups at Medan City Hospital based on nurse satisfaction obtained the $Z$ score is (-

Rani Kawati Damanik*, Adventy Riang Bevy Gulo

Sari Mutiara Indonesia University, Nursing Science Study Program, Indonesia.

${ }^{*}$ Corresponding author. E-mail: rani140387@gmail.com 
Satisfaction among hospital staff nurses on nurse staffing calculation-performance-oriented calculation based on Indonesian National Nurses Association (INNA) on information system

3,742 ) and the value $a=0,000$ where $a<0.05$. Then there are differences in respondent satisfaction with the INNA method information system in calculating the nurse's staff.

\section{DISCUSSION}

Nurses are the largest group of users of information systems. In the future, it is very necessary for nurses to adapt to this. Because it reflects professional nursing practice and improves patient safety (Damanik, 2015). Nurses are the largest group in information system users. Information systems in the future are needed. Therefore, nurses must adapt to it. Because it reflects professional nursing practice and improves patient safety (Zadvinskis, Smith, \& Yen, 2018). Research conducted by [10] which aims to identify the effectiveness of information systems before and after the information system-based nursing care process in the Private Hospital of Medan City. The conclusion was obtained from the test results, namely that there was a difference in effectiveness between before and after the application of information systems in the nursing care process at the Medan City Private Hospital with a value $(p=$ $0.00)$, so $(p<0.05)$, and from the value $t>$ from $t$ table $(16.76>0686)$ with another word $(\mathrm{Ha}: \mu \times 1$ $\neq \mu \times 2$ ), then $\mathrm{Ha}$ Accepted and $\mathrm{Ho}$ rejected.

Information systems in nursing are decision support systems in nursing. Information systems are used to fulfill a variety of nursing goals. Some of the goals of using nursing information systems are to plan and manage nurse resources, measure nursing workload, determine the ratio of nurses to patients in other words, nurse needs, run shifts, and manage and control costs. Furthermore, a system known as nursing management information system is based on patient classification or workload measurement systems (Fathian, Emami, Moghaddasi, Kazemi, \& Rabiei, 2019).

The same thing was also expressed by Karp, et al., (2019) who conducted a study aimed at evaluating the effect of information systems inefficiency service, in this case measuring efficiency by using time. The results showed that the average time spent before the intervention was obtained (mean $=35.93$ ). Meanwhile, after being given the intervention it became (average $=2.55$ minutes). So the time before and after is the system can provide changes between before and after the intervention. Improvement of services nurses through the system can increase the satisfaction of service users at the hospital. Quality services can improve the overall care system and increase user satisfaction. Improved services in nursing care have a positive impact on the quality of care in hospitals (Kartika, \& Hariyati, 2018). The use of information systems in a professional manner is generally with the services implemented. Increasing the use of today's systems requires user support, training, and more computers in the environment. After improving service quality, it must be motivated and supported in its use (Tilahun, \& Fritz, 2015).

The results of research conducted by (Rachmawaty, 2015) show that the development of information systems in nursing greatly affects the process and results of care. Information systems greatly benefit nurses and other health care providers. Information systems can improve the quality of services provided. Nurse satisfaction before and after the application of information systems was compared using thematic analysis and paired t-test. The result was that the information system could increase the satisfaction of nurses as users with a value $(p=0.001)$. So that support from different countries can affect the effectiveness of implementing the system (Hariyati, Hamid, Eryando, \& Hasibuan, 2018).

Nursing needs to develop informatics competencies to encourage professionals to work, ensure accurate nursing data, increase efficiency, be safe, fast and innovative (Labora, Burhanuddin \& Mansyur, 2019). Technology is changing the world very rapidly and that includes the environment of care. Nurses need a speed that suits their needs. Information technology plays a key role, especially with regard to services. The role of technology is to provide solutions that are more cost-effective and faster and develop quality care services (Mohammed, 2018).

Technology is changing the world at breakneck speed in nursing. There are many factors that affect the level of nurse satisfaction (Rizany, Hariyati, Afifah, \& Rusdiyansyah, 2019). The nursing management information system is a

Rani Kawati Damanik*, Adventy Riang Bevy Gulo

Sari Mutiara Indonesia University, Nursing Science Study Program, Indonesia.

${ }^{*}$ Corresponding author. E-mail: rani140387@gmail.com 
Satisfaction among hospital staff nurses on nurse staffing calculation-performance-oriented calculation based on Indonesian National Nurses Association (INNA) on information system

decision support system for nursing managers. The results showed the use of different nursing management information systems that do not use. It is concluded that using various systems can make it easy for nursing to plan and manage its human resources (Fathian, Emami, Moghaddasi, Kazemi, \& Rabiei, 2019). Adopting an information system in the nursing world is important (Ifinedo. 2018). Analysis of the nurse's problem regarding the use of the system in services needs attention. Implementation of information systems can make nurses more effective against time. It was found that the need for system application in the clinical nursing sector has the highest frequency $(88.2 \%)$, (Jeddi, Shaeri, Akbari, Esmaili, \& Farrahi, 2019).

Nurses have a positive attitude towards the use of information systems. The majority $(70-80 \%)$ of them show confidence in using technology (Kuek \& Hakkennes, 2020). The use of the system can also result in satisfaction between the nurse-patient relationship. The system can improve the quality and satisfaction of both (Molina-Mula, \& GalloEstrada, 2020). Information technology has invaded the health sector with many nursing departments being used by it. Technology applications such as information and communication in supporting and providing patient health care in a hospital environment (Lera, Taxtsoglou, Iliadis, Frantzana, \& Kourkouta, 2020).

\section{CONCLUSION}

Based on the results of research on the methods of the Indonesian National Nurses Association on information system acquired the majority of respondents were female $86.7 \%$ in the control group while the intervention group $80 \%$, the majority of $21-52$ year old and $46.7 \%$ in the control group while the intervention group $40 \%$, then the majority of respondents have a Bachelor of Nursing education and $80 \%$ Ners in the control group while the intervention group is $73.3 \%$, and the majority of respondents have a tenure of $0-1$ years 40 in the control group, while the intervention group 0-1 years and $2-5$ years $33.3 \%$. Based on the nurse's satisfaction in the efficiency of the calculation of nurses, it was found that the majority were dissatisfied (score 1-10) of 13 people (86.7\%) in the control group while the intervention group was satisfied (score $11-20$ ) of 13 people (86.7\%).

Nurse satisfaction in the calculation of personnel at the Medan City Hospital has a different value between the control group and the intervention based on the Mean value of 4.66 , then the SE value (standard error) has a difference of 0.13 and based on SD (standard deviation) has a difference of 0.504 , the difference in the Min value is 3 and the Max value difference is 1 . So that there is a difference in the efficiency of the calculation of nurses between the control and intervention groups at Medan City Hospital based on nurse satisfaction. $Z$ score of $(-3,742)$ and the value of $a=0,000$ where $a<0.05$. Then there are differences in respondent satisfaction with the INNA method information system in calculating the nurse's staff. It is recommended to nurses to always update knowledge about technology in nursing so that they can produce services quality nursing.

\section{REFERENCES}

Adegboyega, A., \& Aniefiok, A. J. (2014). Orlando nursing process based healthcare information management system. American Journal of Software Engineering and Applications, 3(5), 56-62.

Alaei, S., Valinejadi, A., Zarein, S., \& Salar, J. (2018). Information Technology (IT) in Hospitals' Nursing Management: Mixed Method Study. International Journal Of Computer Science And Network Security, 18(1), 183-189.

Chand, S., \& Sarin, J. (2019). Confident or Confused: Nurses' Perception and Acceptability of Electronic Nursing Documentation. International Journal of Health Sciences and Research, 9(10), 197-203.

Damanik, R. (2015). Efektifitas Sistem Informasi dalam Proses Dokumentasi Asuhan Keperawatan di Rumah Sakit Swasta Kota Medan. 
Satisfaction among hospital staff nurses on nurse staffing calculation-performance-oriented calculation based on Indonesian National Nurses Association (INNA) on information system

Fathian, A., Emami, H., Moghaddasi, H., Kazemi, A., \& Rabiei, R. (2019). Features of Nursing Management Information Systems: A Systematic Review. Biomedical Journal of Scientific \& Technical Research, 21(2), 1577315781.

Hakami, A., Almutairi, H., Al Otaibi, R., Al Otaibi, T., \& Al Battal, A. (2020). The Relationship between Nurses Job Satisfaction and Organizational Commitment. Health Science Journal, 14(1), 1-5.

Hariyati, R. T. S., Hamid, A. Y., Eryando, T., \& Hasibuan, Z. A. (2018). Usability and satisfaction of using electronic nursing documentation, lesson-learned from new system implementation at a hospital in Indonesia. International Journal of Healthcare Management.

Herlambang, T. W., Aknuranda, I., \& Saputra, M. C. (2017). Pengembangan Sistem Informasi Kesehatan Berbasis Web Berdasarkan Model Organisasi Dan Manajemen Kesehatan Primer "ANDAL". Jurnal Pengembangan Teknologi Informasi dan IImu Komputer e-ISSN, 2548, 964X.

Ifinedo, P. (2018). Empirical study of Nova Scotia nurses' adoption of healthcare information systems: implications for management and policy-making. International journal of health policy and management, 7(4), 317.

Jeddi, F. R., Shaeri, M., Akbari, H., Esmaili, S., \& Farrahi, R. (2019). Behavioral Feasibility of the Clinical Nursing Information System. The Open Nursing Journal, 13(1).

Karp, E. L., Freeman, R., Simpson, K. N., \& Simpson, A. N. (2019). Changes in efficiency and quality of nursing electronic health record documentation after implementation of an admission patient history essential data set. CIN: Computers, Informatics, Nursing, 37(5), 260-265.
Kartika, I. R., \& Hariyati, T. S. (2018). Nelwati. Nurses-patients interaction model and outpatients' satisfaction on nursing care. Nurse Care Open Acces J, 5(2), 70-76.

Kuek, A., \& Hakkennes, S. (2020). Healthcare staff digital literacy levels and their attitudes towards information systems. Health informatics journal, 26(1), 592-612.

Sitinjak,L., Tola, B., \& Ramly, M. (2019). Evaluasi standar kompetensi perawat Indonesia dengan menggunakan model Cippo menuju revolusi industri 4.0 .

Lera, M., Taxtsoglou, K., lliadis, C., Frantzana, A., \& Kourkouta, L. (2020). The use of new information and communication technologies in nursing practice. EAS Journal of Nursing and Midwifery, 2(1), 40-44.

Lin, H. C. (2017). Nurses' satisfaction with using nursing information systems from technology acceptance model and information systems success model perspectives: a reductionist approach. CIN: Computers, Informatics, Nursing, 35(2), 91-99.

Mansoori, M. H., Benjamin, K., Ngwakongnwi, E., \& Al Abdulla, S. (2019). Nurses' perceptions of the clinical information system in primary healthcare centres in Qatar: a cross-sectional survey. BMJ Health \& Care Informatics, 26(1), e100030.

Mohammed, H. M. (2018). New Technology in Nursing Education and Practice. Zagazig Nursing Journal, 14(1), 233-239.

Molina-Mula, J., \& Gallo-Estrada, J. (2020). Impact of Nurse-Patient Relationship on Quality of Care and Patient Autonomy in DecisionMaking. International Journal of Environmental Research and Public Health, 17(3), 835. 
Satisfaction among hospital staff nurses on nurse staffing calculation-performance-oriented calculation based on Indonesian National Nurses Association (INNA) on information system

Orhan, I. (2019). Use of Health Technologies by Nurses and Their Thoughts on Technology. International Journal of Caring Sciences, 12(1), 416-422.

Rachmawaty, R. (2015). The development of the electronic nursing record system (ENRS) in the hospital setting: an integrative literature review. American Journal of Health Sciences (AJHS), 6(1), 1-6.

Rizany, I., Hariyati, R. T. S., Afifah, E., \& Rusdiyansyah. (2019). The Impact of Nurse Scheduling Management on Nurses' Job Satisfaction in Army Hospital: A CrossSectional Research. SAGE Open, 9(2), 2158244019856189.
Tilahun, B., \& Fritz, F. (2015). Comprehensive evaluation of electronic medical record system use and user satisfaction at five low-resource setting hospitals in Ethiopia. JMIR medical informatics, 3(2), e22.

Zadvinskis, I. M., Smith, J. G., \& Yen, P. Y. (2018). Nurses' experience with health information technology: Longitudinal qualitative study. JMIR medical informatics, 6(2), e38. 